\title{
EN ARQUITECTURA: AUSENTES, INVISIBLES, SUPLANTADAS
}

IN ARCHITECTURE: ABSENT, INVISIBLE, SUPPLANTED

\author{
Zoraida Nomdedeu Calvente \\ Arquitecta, EASD Castellón
}

\section{RESUMEN}

No es un tema frecuente en la literatura de ámbito arquitectónico, hablar del lugar que han ocupado las mujeres históricamente en él. La arquitectura va a la zaga de otras áreas del conocimiento y de la actividad humana, en lo referente al tratamiento igualitario de la mujer, bien sea arquitecta o usuaria, por lo que la historia de la arquitectura desde el Renacimiento hasta el Movimiento Moderno, casi carece de referentes femeninas. En este artículo, trataré de demostrar el androcentrismo de las obras clásicas de la teoría arquitectónica, así como de las del Movimiento Moderno y su persistencia en la actualidad. También ilustraré la invisibilización patriarcal de las mujeres tanto en la profesión como en el uso de la obra.

Palabras Clave: Referentes femeninas, invisibilización arquitectónica de mujeres, pioneras, diseñadoras eclipsadas.

\section{ABSTRACT}

It is not a frequent theme in architectural literature, to talk about women historical place. Talking about gender equality, Architecture lags behind other Knowledge and human activity areas, whether architect or user, so Architecture History from the Renaissance to the Modern Movement, almost lacks feminine referents. In this article, I will try to demonstrate the androcentrism of the Architectural Classical Theory works, as well as those from the Modern Movement and its persistence today. I will also illustrate the patriarchal women invisibilization in both the profession and in the use of the work.

Keywords: Female References, Women architectural invisibility, Pioneers, Eclipsed Women Designers.

Abordamos en este escrito la presencia (o, quizá mejor la ausencia o invisibilidad) de las mujeres en arquitectura. Nos encontramos con una disciplina que va a la zaga de otras áreas del conocimiento y de la actividad humana en lo referente al tratamiento igualitario entre géneros. Bien sea como arquitecta o como usuaria, la mujer apenas se toma 
en consideración. La historia de la arquitectura, desde la época clásica hasta el Movimiento Moderno, prácticamente carece de referentes femeninas.

En un texto que quiere repasar la historia de esta ausencia, no podemos dejar de mencionar a Vitruvio, autor de la obra De Arquitectura, escrita en 10 volúmenes y que constituye una compilación de los saberes arquitectónicos grecorromanos. Escrita en el siglo I antes de nuestra era, fue utilizada a lo largo de toda la Edad Media por ser el único texto superviviente (aunque incompleto) de arquitectura clásica. En el Renacimiento se la valora de forma extraordinaria, aunque desde esta época y hasta finales del siglo XVIII, encontramos antivitruvianos y vitruvianos, por lo que la teoría de la arquitectura europea en ese periodo puede resumirse desde la exégesis y la crítica a su obra.

Cuando la Grecia clásica y el Renacimiento ponen al hombre en el centro de todas las cosas, no se refieren al hombre como representante del género humano, sino al hombre como varón. Así se desprende de los textos que nos han llegado. Es el caso de Vitruvio, quien, en el capítulo primero de su tercer libro, expone las proporciones de los órdenes dórico, jónico y corintio: «... una, de aspecto viril y sin ninguna clase de adorno (dórica) y la otra imitando los adornos femeninos (jónica)» (1997: 98). En otro párrafo, afirmaba: «De esta manera, la columna dórica era una respuesta a la proporción del cuerpo humano» (1997: 98).

La lectura de estos dos párrafos evidencia el salto semántico bajo el que se agazapa el androcentrismo que planea en todo el libro. Texto que será referente en estas cuestiones para toda la arquitectura posterior, pues, el antivitruvianismo no se centró precisamente en el análisis androcéntrico del texto. Todavía Loos, a finales del siglo XIX, mantiene la idea de Vitruvio respecto a que la casa debe ser construida teniendo en cuenta el rango y profesión del varón que va a ser su propietario y morador. Y en pleno siglo XXI, Galmés (2014) hace un recorrido del morar a través de doce moradores, varones, salvo dos casos, el matrimonio Eames y el matrimonio Smithson. Son fieles seguidores del androcentrismo de Vitruvio:

Por tanto, quien posea un escaso patrimonio no precisa de vestíbulos suntuosos, ni de recibidores, ni de atrios magníficos, ya que son ellos los que se ven obligados a visitar a otras personas y nadie acude a visitarlos. Los que viven de los productos del campo deben disponer sus establos y sus tiendas en los vestíbulos, y en el interior de la vivienda se situarán las bodegas, graneros y despensas, cuya finalidad es guardar los productos, más que ofrecer un aspecto elegante. Los prestamistas y arrendadores dispondrán de casas más cómodas, más amplias y protegidas frente a posibles manejos ocultos. Los abogados e intelectuales habitarán casas más elegantes y espaciosas, con el fin de celebrar sus reuniones cómodamente; los ciudadanos nobles y quienes ostentan la responsabilidad de atender a los ciudadanos por ejercer cargos políticos o magistraturas, deben disponer de vestíbulos regios, atrios distinguidos, peristilos con gran capacidad, jardines y paseos adecuadamente amplios, en consonancia con el prestigio y la dignidad de sus moradores; 
y además bibliotecas y basílicas que guarden una digna correlación con la magnificencia de los edificios públicos, dado que en sus propios domicilios se celebran decisiones de carácter público (Vitruvio, s.l a.C: 165).

Es obvio que Vitruvio está preocupado por construir la casa adecuada a cada varón, adecuada a su profesión y su estatus social. Es la casa del pater familias. Vivienda y familia son así conceptos que refuerzan la estructura patriarcal (Cevedio, 2010: 71).

Desde un principio, el deseo de Vitruvio de compilar todo el saber arquitectónico grecorromano hasta la época de Augusto tuvo críticos que echaron en falta la coherencia entre ese deseo cerrado, dogmático uniformador y la realidad misma que se mostraba pertinazmente variada. Hasta el siglo XVIII sus seguidores defendían que la falta de coherencia con las ruinas romanas posteriores a Vitrubio era comprensible pues presentaban las variaciones que él mismo autorizaba para adaptar la construcción a la cultura, el clima y los materiales de cada lugar. Además, decían, Vitruvio era helenista, por eso su obra parece ceñirse más a las construcciones griegas. Pero a finales del siglo XVIII la arqueología dio un gran salto y las ruinas griegas fueron descubiertas jtampoco había coherencia con ellas! Pero volvamos al texto de Vitruvio. Su influencia sobre los estudiosos del libro, empeñados en realizar los dibujos supuestamente perdidos es indiscutible. Más bien que escribir sus propios textos, estaban empeñados en limpiar el libro de Vitruvio de sus faltas, carencias y pérdidas, en particular los dibujos supuestamente perdidos y supuestamente necesarios para sacarlo del oscurantismo de su jerga técnica y griega.

Uno de esos dibujos es el llamado Hombre de Vitruvio [Fig. 1] realizado por el propio Leonardo da Vinci en torno a 1490.

Este dibujo sintetiza y confirma la influencia de la idea vitruviana según la cual, el centro, el modelo de simetría y proporción y la medida de todas las cosas, el módulo, es para ambos, el arquitecto clásico y el moderno, el ser humano, tomado como el varón.

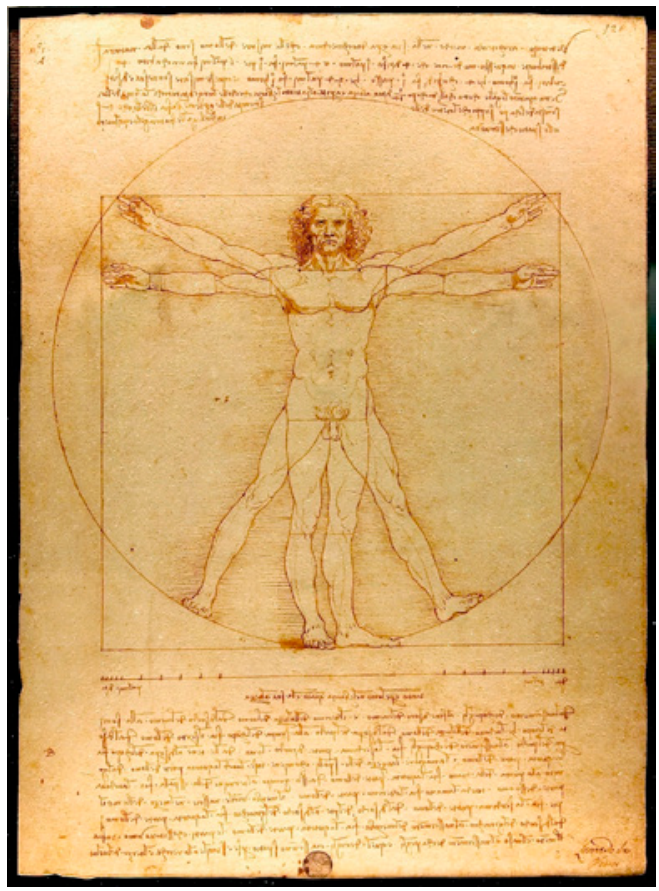

Fig. 1. Leonardo da Vinci. El hombre de Vitrubio, c. 1490. 
En los siglos posteriores, no sólo el módulo será el varón, también las funciones de los objetos arquitectónicos toman como modelo al hombre. Escuchemos la voz de Filarete en el siguiente párrafo:

The building is conceived in this manner. Since no one can conceive himself without a woman, by another simile, the building cannot be conceived by one man alone. As it cannot be done without woman, so he who wishes to build needs an architect. He conceives it with him and then the architect carries it. When the architect has given birth he becomes the mother of the building. Before the architect gives birth, he should dream about his conception, think about it, and turn it over in his mind in many ways for seven to nine months, just as a woman carries her child in her body for seven or nine months. He should also make various drawings of this conception that he has made with the patron, according to his own desires. As the woman can do nothing without the man, so the architect is the mother to carry this conception. When he has pondered and considered and thought [about it] in many ways, he ought to choose [according to his own desires], what seems most suitable and most beautiful to him according to the terms of the patron. When this birth is accomplished, that is when he has made, in wood, a small relief-design of its final form, measured and proportioned to the finished building, then he shows it to the father ${ }^{1}$ (Filarete, ca. 1465: 15).

Pero no sólo impone su cuerpo como modelo en la construcción de los edificios nobles y se travestiza en madre generadora y paridora de su obra arquitectónica, sino que, tanto el interior como el exterior de los edificios, debe estar al servicio de las necesidades del hombre, del usuario, del padre de la obra: el varón, tal como podemos leer en el siguiente párrafo de Francesco di Giorgio:

In prima adunque è da sapere ce la Piazza principale debba nel centro della terra, o più propinqua a quello che si puo, essere locata, come il bellico del l'vomo, la quale alla comodità deba essere seconda. E la ragione della similitudine può essere questa: perchè siocome per un bellico nel principio la natura umana piglia nutrimento e perfexione, così per questo luogo comune gli altri proprii sono sovvenuti. Ma la ragione naturale è in

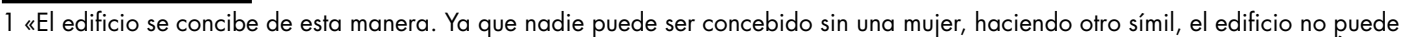
ser concebido por un solo hombre. Como no se puede hacer sin la mujer, también quien desea construir necesita un arquitecto. Él concibe con el arquitecto y luego el arquitecto lo gesta. Cuando el arquitecto ha dado a luz se convierte en la madre de la construcción. Antes de que el arquitecto dé a luz, debe soñar con su concepción, pensar en ello, y darle la vuelta en su mente de muchas maneras durante siete a nueve meses, al igual que una mujer lleva a su hijo en su cuerpo durante siete o nueve meses. También debe hacer varios dibujos de esta concepción que él ha hecho con el patrón, de acuerdo con sus propios deseos. Así como la mujer no puede hacer nada sin el hombre, el arquitecto es la madre para llevar adelante esta concepción. Cuando él ha meditado y considerado y pensado [al respecto] de muchas maneras, debe elegir [de acuerdo con sus propios deseos], lo que le parece más adecuado y más hermoso, de acuerdo a los términos del patrón. Cuando se logra este alumbramiento, que es cuando ha hecho, en madera, un pequeño diseño de su forma final, medido y proporcionado al futuro edificio terminado, entonces lo muestra al padre» (Traducción propia).
} 
pronto, perchè tutte le cose comuni debbano alle proprie essere indifferenti² (Di Giorgio, 1841: 73).

Si tenemos en cuenta que la ciudad es para Di Giorgio como una casa pero a gran escala, podemos deducir qué piensa sobre las funciones de la misma y por tanto en beneficio de quién hay que adaptar la construcción.

En la época de la llustración, poco cambian las cosas. Para las edificaciones del pueblo todo sigue igual, pero éstas no figuran en los tratados de arquitectura. En las altas esferas, se dirime la lucha por el poder entre la nobleza y la burguesía. La Revolución Francesa alienta, dirige al pueblo con sus eslóganes de Libertad, Igualdad y Fraternidad, pero cuando Olympe de Gouges pide la igualdad entre mujeres y hombres, es guillotinada. El pueblo cambia de amos, pero no de posición. Los grandes edificios son construidos ahora por la burguesía y los arquitectos siguen las normas, las pautas que escribiera por primera vez Vitruvio y desarrollarán más tarde los renacentistas. Habrá que esperar a que las revoluciones sociales de mediados del siglo XIX posibilitaran a principios del siglo XX nuevas visiones a las pioneras, mujeres que abren caminos en el mundo de la arquitectura y que aún hoy reciben escaso reconocimiento en proporción a sus logros y contribuciones. El pueblo llano sigue autoconstruyendo sus viviendas u ocupando las infraviviendas de colonias fabriles, o viviendo de alquiler en las casas construidas en serie por la oligarquía burguesa, al estilo del resto de la producción industrial.

Ninguna mujer arquitecta, ninguna consideración a las experiencias, los deseos o necesidades de las mujeres, ningún reconocimiento a sus derechos, sólo invisibilización en el mejor de los casos o la usurpación de su identidad en casos como en la cita de Filarete en la que la capacidad de concebir se traspasa al hombre arquitecto varón.

Las excepciones a esta omnipresencia de varones arquitectos, existieron ya en el cartesiano siglo XVII: Plautilla Bricci, que ejerció y se la recuerda como hermana del arquitecto romano Basilio. Esta vinculación y el hecho de estar a la sombra de los hombres de su entorno familiar serán constantes entre las excepciones mencionadas de mujeres arquitectas hasta bien entrado el siglo XX. Tras este caso de Plautilla Bricci no volveremos a encontrar nombres de mujeres en la historiografía de la arquitectura hasta finales del siglo XIX. Algunas pasarán a la historia por su relevancia como interioristas, otras por ser las primeras en acceder a las instituciones educativas. Su mérito será ensombrecido casi siempre por el brillo de su padre,

2 «Por lo tanto, decir que, en primer lugar, la plaza principal se debe colocar en el centro de la ciudad o lo más cerca posible, al igual que el ombligo en el cuerpo del hombre, la utilidad debería ir en primer lugar. La razón de esta similitud podría ser la siguiente; al igual que es a través del ombligo que la naturaleza humana obtiene la nutrición y la perfección en sus inicios, de la misma manera desde la plaza principal, común, se sirven otros lugares particulares» (Traducción propia). 
hermano o esposo arquitecto, entre cuyos méritos no es el menor el de disfrutar de privilegios sociales debidos a su clase social y a su sexo, como en los inicios de la Antigüedad Clásica, como en el Renacimiento, como en las primeras vanguardias, como hoy en el star system.

Pero sigamos con esa historia androcéntrica, vacía de mujeres. La revolución industrial favorece la emergencia de una arquitectura en hierro, cristal y hormigón, como el Cristal Palace de Londres que albergó la primera exposición universal de diseño industrial (1887), la Torre Eiffel construida en París para la exposición universal de 1889 o la de Tatlin (1919) destinada a sede de la Internacional Comunista en Moscú. El modernismo intentará romper con ese estilo lineal y frío aportando su estilo naturalista orgánico, aunque aprovechando los nuevos materiales, que mezclará casi artesanalmente con los materiales nobles tradicionales. La disciplina de la arquitectura controlará todo el proceso, desde el diseño de los objetos y muebles, pasando por el diseño de interiores hasta el proyecto propiamente arquitectónico, coherente con el resto del trabajo en el interior. Ya hemos visto antes que no será un trabajo tan en solitario, pues esos interiores serán responsabilidad en muchas ocasiones de esas primeras mujeres, a las que sólo se les dejará ese espacio profesional en su intento de aproximarse a la arquitectura (Novas, 2014: 20-23).

Pero la transición modernista durará poco, el funcionalismo del Movimiento Moderno romperá con todos los estilos, historicistas o innovadores, aunque mantendrá los cánones de las proporciones.

Tras la Primera Guerra mundial confluyeron varios factores: la necesidad de reconvertir la industria armamentística -y los avances tecnológicos acaecidos como consecuencia de la guerra - en una industria para los tiempos de paz, por ejemplo en industria de la construcción; la conveniencia de utilizar los nuevos materiales descubiertos entre el final del siglo XIX y principios del XX - hierro fundido, cristal y hormigón armado- la antigua necesidad de viviendas populares, exacerbada ahora y la disponibilidad de suelo edificable, como consecuencia de la destrucción ocasionada por la guerra. Esta confluencia de factores llevó a arquitectos como Mies Van der Rohe, Gropius y Le Corbusier a divorciarse de la tradición clásica de los órdenes arquitectónicos y a crear una nueva arquitectura: el Movimiento Moderno, la Nueva Construcción, el funcionalismo, más allá del mero racionalismo.

Por otro lado, mientras los hombres estuvieron en el frente, las mujeres ocuparon sus lugares en fábricas, talleres y estudios. También en arquitectura. Así se incorporaron las pioneras al Movimiento Moderno. Una nueva arquitectura cuyo referente principal fue la Bauhaus, fundada en el año 1919 por Gropius quien, a pesar de abrir las puertas de la escuela a las mujeres, se las cerró a los talleres de arquitectura; fue así como la mayoría de ellas se inscribieron en talleres de diseño como el textil. 
Ante una Europa arrasada, ése era el espíritu con que varios arquitectos, y como veremos, también arquitectas, ven la oportunidad y abordan la tarea de construir muchas viviendas en poco tiempo y con poco gasto para dar alojamiento a las gentes que llevan décadas viviendo en las cassernes y que, además, ahora han quedado desahuciadas por tanta devastación, erigiéndose así en continuadores de los proyectos de vivienda popular preexistentes en América, Europa central y Europa del este. También ven la oportunidad de dar un aprovechamiento de posguerra a la industria armamentística. Así surge el proyecto de la producción de viviendas en serie de Le Corbusier, ligado a la industria de aeronaves. En su obra Hacia una arquitectura escribió:

...se han producido en las fábricas tantos cañones, aviones, camiones y vagones, uno se dice ¿ No se podrían fabricar casas? [...] la casa ya no será esa cosa pesada y que pretende desafiar los siglos, el objeto opulento por el cual se manifiesta la riqueza, será una herramienta, como lo es el auto (Le Corbusier, 1923: 197).

Esta frase que condensa la idea corbuseriana de la casa como una máquina para vivir, parece un faro que guiará los experimentos arquitectónicos durante todo el siglo XX y los comienzos de este siglo.

El sesgo de género de la producción teórica y práctica de esta arquitectura resulta innegable. Baste decir ahora que un discípulo de Gropius en la Bauhaus, Ernst Neufert - un mitlaufer (adepto colaborador o simpatizante) que permaneció al servicio del Tercer Reich, ocupando cargos relevantes en la Escuela de Arquitectura de Weimar durante la guerra- es el autor de El arte de proyectar en arquitectura, un libro eminentemente visual que se ha convertido en una especie de enciclopedia técnica para todos los estamentos relacionados con la industria de la construcción, y cuyo androcentrismo queda patente en imágenes como la que reproducimos a continuación [Fig. 2].

La producción de viviendas en serie abría la esperanza de resolver el problema de habitación a las clases populares, pero era necesaria una voluntad política para financiarla. Por eso, aunque se hicieron intentos en casi

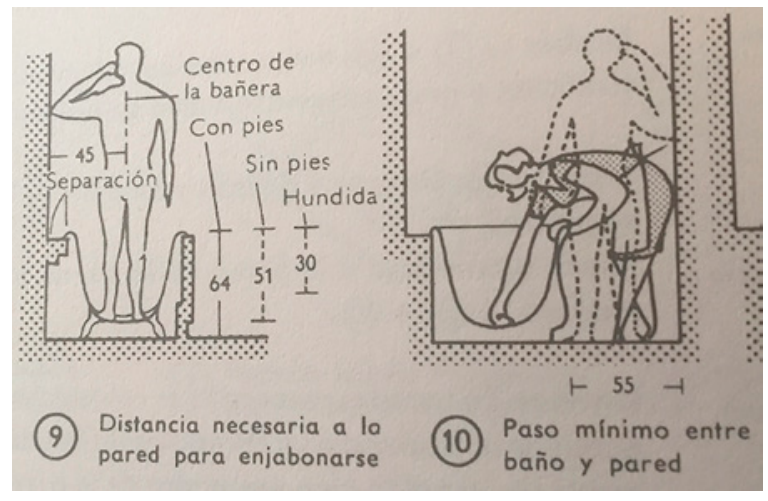

Fig. 2. Ernst Neufert. Ilustraciones androcéntricas y estereotipadas en el libro El arte de proyectar en arquitectura, 1991. 
todos los países europeos, sólo cabe remarcar algunos logros como el proyecto de la Nueva Frankfurt (1925-1930) en Alemania, el de vivienda popular en Austria durante el periodo de la Viena Roja (1923-1933) y el proyecto colectivista Narkomfin (1928-1932) en Rusia.

Del artículo «La vivienda popular en el movimiento Moderno» escrito por Auke van der Wonde, extraeremos algunas ideas al respecto. Desde 1875, dos procesos se dieron simultáneamente: la revolución industrial en el sector de la construcción y el aumento de la demanda de vivienda. Estas circunstancias impulsaron a los arquitectos modernos a reorientar su trabajo profesional. En 1927, en Sttutgart, se celebró una exposición con dos ejes directores: una nueva forma de construir y una nueva forma de vivir, pero la realización de dicho proyecto tuvo lugar en Franckfurt: donde Ernst May y un equipo de arquitectos entre los que se encontraba Margarete Schütte-Lihotzky, construyeron 25 colonias bajo la estandarización más radical. Las 11-12000 viviendas así construidas surgieron de 13 tipos y 8 variantes. La vivienda mínima tenía $37 \mathrm{~m}^{2}$, en algunas viviendas había muebles empotrados, incluso una cocina estándar, diseñada por Margarete, pensada para aliviar el trabajo doméstico del ama de casa. Eran viviendas populares, contemplaban un igualitarismo para la clase obrera, pero no para los géneros. Sólo cuando la crisis del 29 hizo emigrar a los arquitectos alemanes a Rusia, que se hallaba en pleno desarrollo de sus planes quinquenales, se diseñaron viviendas colectivas en las que cocina, comedor, lavandería o guardería, eran comunitarias, tal como anunció Alexandra Kollontai:

En la Rusia Soviética, la vida de la mujer trabajadora debe estar rodeada de las mismas comodidades, la misma limpieza, la misma higiene, la misma belleza, que hasta ahora constituía el ambiente de las mujeres pertenecientes a las clases adineradas. En una Sociedad Comunista la mujer trabajadora no tendrá que pasar sus escasas horas de descanso en la cocina, porque en la Sociedad Comunista existirán restaurantes públicos y cocinas centrales en los que podrá ir a comer todo el mundo.

Estos establecimientos han ido en aumento en todos los países, incluso dentro del régimen capitalista. En realidad, se puede decir que desde hace medio siglo aumentan de día en día en todas las ciudades de Europa; crecen como las setas después de la lluvia otoñal. Pero mientras en un sistema capitalista sólo gentes con bolsas bien repletas pueden permitirse el gusto de comer en los restaurantes, en una ciudad comunista estarán al alcance de todo el mundo.

Lo mismo se puede decir del lavado de la ropa y demás trabajos caseros. La mujer trabajadora no tendrá que ahogarse en un océano de porquería ni estropearse la vista remendando y cosiendo la ropa por las noches. No tendrá más que llevarla cada semana a los lavaderos centrales para ir a buscarla después lavada y planchada. De este modo tendrá la mujer trabajadora una preocupación menos.

La organización de talleres especiales para repasar y remendar la ropa, ofrecerán a la 
mujer trabajadora la oportunidad de dedicarse por las noches a lecturas instructivas, a distracciones saludables, en vez de pasarlas como hasta ahora en tareas agotadoras.

Por tanto, vemos que las cuatro últimas tareas domésticas que todavía pesan sobre la mujer de nuestros tiempos desaparecerán con el triunfo del régimen comunista.

No tendrá de qué quejarse la mujer obrera, porque la Sociedad Comunista habrá terminado con el yugo doméstico de la mujer para hacer su vida más alegre, más rica, más libre y más completa (Kollontai, 1918: 10).

Un $25 \%$ de viviendas fueron construidas según este modelo. Pero las arquitectas alemanas progresistas y sus compañeros arquitectos tuvieron poco respiro, si en 1930 fueron expulsados de Alemania bajo la acusación de bolcheviques, en 1932 tuvieron que abandonar Rusia bajo la acusación de funcionalistas capitalistas (Van der Wonde, 1999: 5-18). Durante la misma década fueron construidas las viviendas sociales de la Viena Roja [Figs. 3, 4, 5, 6 y 7]:
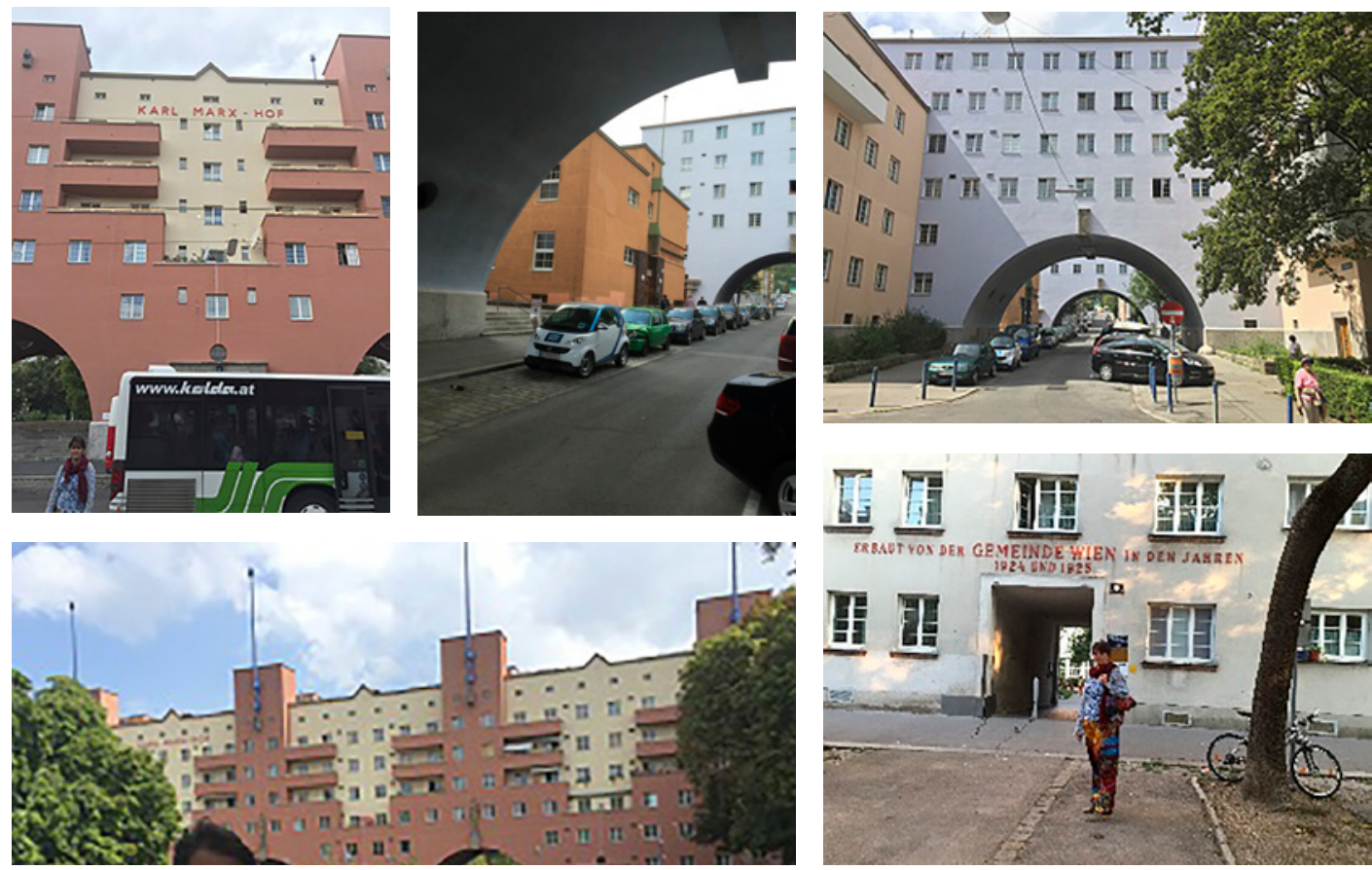

Figs. 3, 4, 5, 6 y 7. Hoff en La Viena Roja. Fotografías de la autora, 2015.

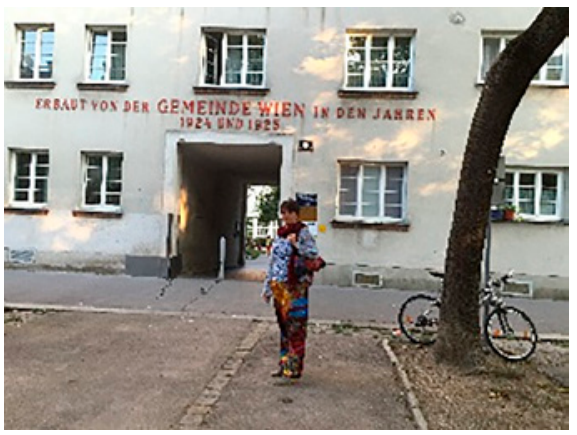


En las que destacan [Figs. 8, 9, 10, 11, 12 y 13] sus servicios colectivos:
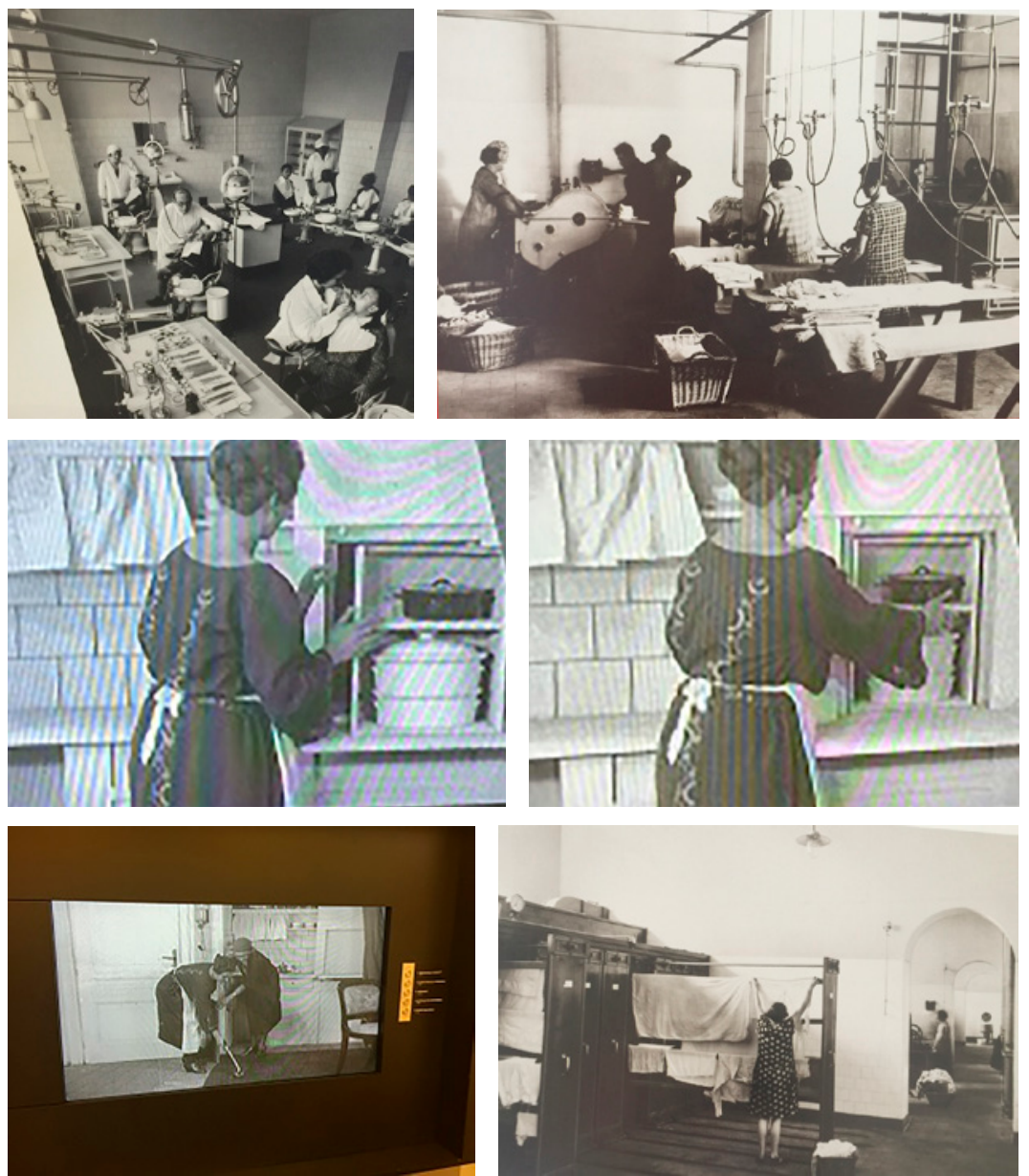

Figs. 8, 9, 10, 11, 12 y 13. Exposición en el recinto de la lavandería de la Karl-Marx Hoff en La Viena Roja. Fotografía de la autora. 
Las clases trabajadoras seguirán concentradas en las viviendas sociales, hasta que la irrupción del neoliberalismo las dispersará. El modelo colectivista de la Viena Roja simbolizará el deseo de proporcionar a la mujer de la clase obrera no sólo una vivienda mínima sino una vida digna. Más de cinco décadas después de la proyección, ejecución y declive de estos proyectos vieneses de vivienda popular con servicios comunitarios, las arquitectas feministas occidentales, retomaron el modelo colectivista.

Posteriormente la guerra fría enfrentaba el modelo colectivista ruso con el consumista americano. Multitud de experimentos se desarrollan en Estados Unidos, a donde fueron a parar los arquitectos emigrantes. Desde la casa como un coche al coche habitable se llega a la vivienda en movimiento a través de múltiples proyectos, la mayoría de los cuales no alcanzarán la fase de ejecución, salvo la caravana y la autocaravana que conocerán una gran expansión, primero como objeto de lujo de las clases medias más acomodadas y luego como vivienda de sectores nómadas de la población. Otros experimentos serán la casa cápsula, la casa electrodoméstico o la casa traje, todos paralizados en la fase experimental, aunque cada uno de ellos ha abierto nuevos caminos para resolver los problemas de la nueva vivienda en una sociedad consumista cuyo estilo de vida es el de usar y tirar, el del movimiento, el de lo efímero, el cambio permanente, la moda.

Incluso en estas casas experimentales hipermodernas, podemos encontrar tics patriarcales que filtran subrepticiamente el papel de subalterna de la mujer, a través del máximo representante de la Moderna Arquitectura, Le Corbusier:

Nuestras necesidades son necesidades de hombres [...] Si somos quince en el pequeño salón de la pequeña casa, que han venido decididos a no hacer nada, el ama de casa ha sacado de dentro del armario empotrado los quince taburetes, encajados uno en otro (Le Corbusier, 1942: 142).

Hoy la mayoría de las mujeres del mundo occidental acomodado conducen, sin embargo, una estadística sencilla nos muestra que las caravanas y autocaravanas, como los vehículos pesados, son conducidas por varones. Según el censo de la Dirección General de tráfico, en 2013 obtuvieron el carnet $B, B+E, A \circ A 24.825$ mujeres, frente a 391.350 varones. La caravana es una máquina, como lo es el coche y ellos tienen asignado socialmente el rol de «mecánicos» del hogar. Si el propio hogar es una máquina pesada, las tareas domésticas quedan asignadas por exclusión, ellos son quienes pueden conducirla por su tamaño, quienes entienden su mecánica, quienes la utilizan como signo de riqueza. Ellas se ocuparán de las tareas domésticas, en cocinas diminutas, dormitorios incómodos, aseos con limitadas condiciones de higiene, todo soportable cuando su uso es vacacional, pero absolutamente 
precario cuando la casa rodante se ha convertido en vivienda habitual. Esta cuestión queda clarificada si se usa el concepto de escenario de género inscrito en los objetos, en el sentido de la interacción entre género y objeto:

La notion de scénario (de genre) souligne l'existence de deux procesus en jeu dans le façonement réciproque du genre et des objects technologiques. Tout d'abord, un object peut devenir sexué si ses créateurs anticipent les préférences, les motivations, les goûts et les compétences des utilisateurs potenciels, ainsi que les normes culturelles de la société dans son ensemble. De telles anticipations se matérialisent ensuite dans la conception technologique du nouveau produit. En second lieu, les objects dotés d'un scénario de genre peuvent façoner et définir les actions des femmes et des hommes. En raison des normes et des valeurs inscrites dans un object technique, le dit object peut atribuer et conférer des rôles, des actions et des responsabilités spécifiques à leurs vilisateurs ${ }^{3}$ (Oudshoorn, 2009: 306).

Los datos de la DGT nos hablan claramente de cuál es el escenario de género de un tipo particular de objetos tecnológicos, los vehículos a motor. Muchos otros objetos tecnológicos serán producidos en esta época con distintas adscripciones de género, los electrodomésticos en particular. Las autoras de la cita anterior, analizan la exposición Objects $\mathrm{f} / \mathrm{m}$. Le design sexué des objects de la vie quotidienne, que tuvo lugar en la Universidad de Twente en 1996 y en el museo New Metropolis de Amsterdam en 1997, y, por un lado, confrontan los diseños de un microondas con una cadena hi-fi; $y$, por otro, dos modelos de rasuradora, la Ladyshave y la Philishave, para mujer y hombre respectivamente. Sobre la segunda de las comparaciones observan:

Tout d'abord, d'enormes differences de représentation des utilissateurs masculins et féminins sont inscrites dans ces objects. La femme est représentée comme un utilisateur qui préfère les couleurs pastel et les formes arrondies, en cherche pas à tripoter des objects technologiques, en s'interesse pas aux gadgets et préfère rester chez elle. Par opposition, l'homme est représenté comme un utilisateur qui préfère les couleurs sombres et les formes anguleuses,

3 «El concepto de escenario (de género) subraya la existencia de dos procesos en juego en la configuración mutua del género y los objetos tecnológicos. En primer lugar, un objeto puede convertirse en sexuado si sus creadores anticipan preferencias, motivaciones, gustos y habilidades de las personas usuarias potenciales, así como las normas culturales de la sociedad en su conjunto. Tales expectativas se materializan más adelante en el diseño tecnológico del nuevo producto. En segundo lugar, los objetos tienen inscrito un escenario de género que puede crear la ventaja competitiva y definir las acciones de las mujeres y los hombres. Debido a las normas y valores consagrados en un objeto técnico, dicho objeto puede atribuir y conferir funciones, acciones y responsabilidades específicas a sus usuarios» (Traducción propia). 
aime jouer avec des objects technologiques, adore les gadgets et mène une vie nomade 4 (Oudshoorn, 2009: 306).

Los visitantes de la exposición, en la que también había bicicletas, ordenadores, videojuegos, perfumes, rellenaron un cuestionario y la mayoría de ellos concluyó que los objetos expuestos poseen, de una forma determinada, un género.

Las casas experimento, fueron, ellas mismas, objetos tecnológicos y, como veremos, mantienen inscritos escenarios de género. En cuanto a las mujeres que intervinieron en estos experimentos, fueron captadas desde el mundo del diseño y el interiorismo y sus nombres van acompañados por el de sus maridos con el único apellido de éstos que, por las leyes de familia vigentes, es el que sustituye al propio en la mayor parte de países del Norte. Es decir, fueron eclipsadas en lo civil y en lo profesional.

Mientras tanto, en las casas experimentales seguían copiando los procedimientos constructivos de la industria de guerra e iban a ser destinadas a configurar la identidad de las nuevas familias consumidoras. Casi a un tiempo se expandió el modelo arquitectónicomediático Playboy que configuró la identidad del nuevo varón consumidor de placeres y su contraparte, la mujer sexi, al estilo Marilyn, según la investigación que desarrolla Beatriz Preciado en su libro Pornotopía: arquitectura y sexualidad en Playboy durante la guerra fría:

En plena guerra fría, el joven Hug Hefner crea la que pronto se convertirá en la revista para adultos más vendida del mundo: Playboy. Lo que el público desconoce es su pionera labor como artífice de las casas del placer. Playboy no era simplemente una revista de chicas con o sin bikini, sino un vasto proyecto arquitectónico-mediático que tenía como objetivo desplazar la casa heterosexual como núcleo de consumo y reproducción proponiendo frente a ésta nuevos espacios destinados a la producción de placer y capital. Esta podría ser la divisa de Playboy: si quieres cambiar a un hombre, modifica su apartamento. De la misma manera que la sociedad ilustrada creyó que la celda individual podía ser el enclave de reconstrucción del alma criminal, Playboy confió a la mansión de soltero la fabricación del nuevo hombre moderno (Preciado, 2010, 413).

Esto son claros ejemplos de que el espacio habitado sí define, según nuestra sociedad, el proceso de construcción de la propia identidad.

4 «En primer lugar, en estos objetos están inscritas las enormes diferencias en la representación de usuarios masculinos y femeninos. Las mujeres están representadas como usuarias que prefieren los colores pastel y las formas redondeadas, que no buscan relacionarse con los objetos tecnológicos, no les interesan los aparatos y prefieren quedarse en casa. Por el contrario, el hombre es representado como un usuario que prefiere los colores oscuros y formas angulares, le gusta jugar con objetos tecnológicos, ama los aparatos y lleva una vida nómada» (Traducción propia). 
Se hace necesario un rescate de la historia completa, una manera inclusiva de contar cómo las aportaciones profesionales de determinadas mujeres han enriquecido los espacios habitables. Cabe reseñar sus logros, muchas veces atribuidos a compañeros de vida cuya trayectoria profesional muestra la influencia de estas mujeres al virar hacia estándares diferentes a los que manejaban antes de colaborar con ellas y que, en los casos en los que esta colaboración se ve truncada, podemos detectar cómo se difuminan por la falta de impulso de sus creadoras.

Ensombrece la aportación de estas mujeres, incluso la fagocita, el modo en el que se traslada su participación en la historia de la arquitectura, o quizás como se traslada la participación de ellos. ¿̇Hemos leído alguna vez una aclaración que verse sobre Alvar Aalto, pareja de Aino Marsio Aalto y en segundas nupcias de Elissa Aalto, cuya finalidad fuera ubicar a Alvar Aalto? No, él ya está ubicado, aunque esto no le convierta en el verdadero diseñador de toda la producción que surge de la colaboración con Aino en una etapa de su vida y con Elissa posteriormente. A él se le entiende legitimado sobre la autoría global, a ellas, sin embargo, incluso al escribir sobre aspectos desarrollados en primera persona, se las deslegitima a este respecto, sembrando la duda sobre dicha autoría al definirlas no como ellas mismas sino como pareja de él:

La incorporación activa de la mujer como profesional a la evolución de la sociedad es, tal vez, el parámetro más importante de la modernidad de nuestro siglo; y su transformación de objeto de la industria a sujeto de la misma ha sido un exponente de dicha modernidad. Margarete MacDonald (Charles Renie Mackintosh), Anna Muthesius (Hermann Muthesius), Eileen Gray (Jean Badovici), Lilly Reich (Ludwig Mies van der Rohe), Truus Schröeder (Gerrit Rietveld), Marlene Poelzig (Hans Poelzig), Grete Shütte Lihotzky (Ernst May), Aino Marsio Aalto (Alvar Aalto), Lote Stam-Beese (Mart Stam), Ray Eames (Charles Eames) y Charlotte Perriand (Le Corbusier y otros) han sido algunas de las escasas mujeres que han intervenido como sujetos históricos de la industrialización arquitectónica, aunque sus trabajos hayan resultado eclipsados, sin excepción por los conocidos nombres de sus compañeros y/o colaboradores (Espegel, 1996: 60).

Este texto de Carmen Espegel es claro respecto a la situación de deslegitimación de la que hablamos, e incluso más allá, me atrevería a dudar de la expresión «han sido algunas de las escasas mujeres que han intervenido como sujetos históricos de la industrialización arquitectónica», planteando que a lo largo de la historia no cabe afirmar categóricamente que no haya habido otras mujeres cuya intervención como sujeto histórico aun habiendo existido, no haya trascendido. La invisibilización, como todas las estructuras de violencia, tiene diferentes grados. Haber contribuido bajo seudónimos masculinos y nunca llegar a ser 
descubiertas, haber aportado como equipo de trabajo a la producción de varones vinculados a ellas y nunca haber sido reconocidas, son situaciones que no podemos negar que se hayan dado a lo largo de siglos de producción en el ámbito de la arquitectura o el diseño de interiores.

Afortunadamente ya hay, a día de hoy, diferentes acciones que están en marcha con el objetivo de corregir la situación de invisibilización que aquí se denuncia. La cuarta edición de Un día / Una arquitecta ${ }^{5}$ es una de ellas. Esto supone más de 700 nombres de mujeres en una versión consultable que sigue incrementando el listado.

La construcción del conocimiento es una cuestión colaborativa que implica a todos los agentes sociales. Quizá la posibilidad de acceder a esos conocimientos de manera múltiple y variada en las plataformas online pueda ser una vía a seguir. Debemos generar la información real que completa el puzzle del conocimiento y, simultáneamente, facilitar el acceso a esos contenidos para todas aquellas personas en quienes se despierte el interés por la coeducación, desde cualquier ámbito.

Me plateo seriamente la necesidad de ir más allá. No podemos quedarnos en la obligatoria tarea de intercalar nombres de mujeres en la historia de la arquitectura y el diseño. Debemos, sin duda, revisar las bases según las que la misma historia se ha escrito.

\section{Bibliografía}

CeVEDIO, Mónica (2010). Arquitectura y género, Barcelona: Icaria.

DI GIORGIO, Francesco (1841). Trattato di architettura civile e militare, Torino: Tipografia Chirio e Mina.

Dirección General de Tráfico (2013). Censo de conductores por clase, sexo y edad, en Formación Vial, DGT, Ministerio del Interior, http://www.dgt.es/es/seguridad-vial/estadisticas-e-indicadores/censo-conductores/por-clase-sexo-y-edad/ [Fecha de consulta 16/05/2016].

EsPegel, Carmen (1996). «El arte de vivir. Charlotte Perriand y el hábitat moderno» en Arquitectura Viva Núm. 48, Madrid: Arquitectura Viva, pág. 60.

Filarete (Antonio Averlino llamado) (ca. 1465), Treatisse on Architecture, London, Yale University Press, 1965. 
_ (ca. 1465). Trattato di architettura, Biblioteca Italiana.

http://www. bibliotecaitaliana. it/xtf/view? docld=bibit000307/bibit000307. $x m$ \& chunk. $i d=d 3733$ e 138\&toc. depth $=100 \&$ toc. $i d=d 3733$ e 133\&brand $=$ newlook [Fecha de consulta 19/04/2015].

Galmés Cerezo, Álvaro (2014). Morar, arte y experiencia de la condición doméstica, Madrid: Universidad Europea.

Kollontal, Alexandra (1918). El comunismo y la familia, Archivo Kollontai on line https://www. marxists.org/espanol/kollontai/1918/001.htm [Fecha de consulta, 13/05/2016]

LE CORBuSIER, Charles-Édouard (1923). Hacia una arquitectura, Barcelona: Apóstrofe, 1998 (2ª ed.). https://www.academia.edu/6468653/Le_Corbusier_-_Hacia_Una_Arquitectura_PDF, [Fecha de consulta 01/06/2014].

_ (1942). La casa del hombre, Madrid: Apóstrofe, 1999.

NovAs, María (2014). Arquitectura y Género. Una reflexión teórica, Trabajo Fin de Máster dirigido por Rosalía Torrent, Castellón, Instituto de Estudios Feministas y de Género Purificación Escribano: Universitat Jaume I.

Oudshoorn, Nelly, Rudinow SAETAN, Ann et Merete Lie (2009). «Du genre et des réflexions sur une exposition d'objects sexués» en Morineau, Camille et Annalise Rimmando (dirs.) (2009). elles@centrepompidou. Artistes femmes dans la collection du musée d'art moderne. Centre de creation industrielle, Paris: Centre Pompidou, pp. 304-308.

PrECIADO, Beatriz (2010). Pornotopía: arquitectura y sexualidad en Playboy durante la guerra fría, Barcelona: Anagrama.

Vitruvio Polion, Marco (s.I a.n.e), Los diez libros de arquitectura de Vitrubio, Madrid: Alianza Editorial, 1997.

Woude, Auque van der (2010). «La vivienda popular en el movimiento moderno», en Cuadernos de notas 7, http://www.aq.upm.es/Departamentos/Composicion/webcompo/ webcnotas/pdfs/CN7_1_Vivienda\%20Popular.pdf, (traducido por Rafael García) [Fecha de consulta 28/06/2015].

Recibido el 24 de abril de 2018

Aceptado el 23 de junio de 2018

BIBLID [1 139-1219 (2018) 32: 95-110] 